\title{
PASTORAL UNIVERSITÁRIA: a Universidade Católica a serviço da evangelização
}

\author{
Pastoral care at the university level: an \\ evangelizing role for a Catholic University
}

\section{Clemente Ivo Juliatto}

Reitor da Pontifícia Universidade Católica do Paraná, Doutor e pós-doutor em educação pela Universidade de Harvard e Columbia, Nova Iorque, EUA, Curitiba, PR - Brasil, e-mail: reitor@pucpr.br

\section{Resumo}

A ação evangelizadora da Universidade Católica realiza-se de muitas maneiras, sobretudo naquilo que é próprio da prática educativa no ensino superior. Contudo, a Pastoral Universitária é um campo privilegiado para o desenvolvimento da missão que a Universidade Católica tem de anunciar o Evangelho e de promover o frutuoso diálogo entre fé e cultura e entre fé e razão. O presente artigo intenta descrever as principais linhas de orientação para uma Pastoral Universitária na Universidade Católica, em fidelidade à mensagem do Evangelho e ao ensinamento da Igreja. $\mathrm{O}$ texto também apresente linhas de ação e pistas metodológicas para o incremento das práticas pastorais e das ações de evangelização nas instituições católicas de educação superior.

Palavras-chave: Universidade católica; Pastoral; Evangelização; Igreja. 


\begin{abstract}
The evangelizing mission of a Catholic University may be carried out in many ways, mainly through what is the characteristic educational practice in higher learning. Pastoral care at the university level is a privileged field for the development of the mission that the Catholic University has in announcing the Gospel and promoting a fruitful dialogue between faith and culture, between faith and reason. This paper tries to describe the main guidelines to orient pastoral work in a Catholic University, in line with the Gospel and the teaching of the Church. The text also presents action plans and methodological hints to better pastoral practices and to evangelizing actions in Catholic Institutions of Higher Learning.
\end{abstract}

Keywords: Catholic university; Pastoral; Evangelization; Church.

\title{
Introdução
}

A Universidade Católica, em razão de sua identidade confessional, traduz nas atividades de ensino, pesquisa e extensão, seu modo peculiar de anunciar a mensagem cristã. Evangelizar significa, ao mesmo tempo, testemunhar e anunciar o Evangelho, istoé, viver e proclamar as exigências da mensagem cristã. Jesus ordenou a seus discípulos que fossem pelo mundo afora, pregando o Evangelho, anunciando a todos os povos, raças e culturas a sua mensagem de amor ao próximo. A ordem de Jesus - "Ide e evangelizai a toda criatura" - não tem apenas uma conotação geográfica e cultural que engloba todas as regiões e raças do mundo, mas também uma referência a todas as classes e ambientes sociais, incluindo o mundo dos intelectuais e o ambiente universitário. Reconhecemos, com alegria e entusiasmo, que "cresce, em muitos educadores, religiosos e leigos, a consciência de que sua prática educativa precisa ser sempre mais uma presença da Igreja evangelizando o mundo da educação" (CNBB, 1992, n. 49). Em sintonia com as orientações do episcopado latinoamericano, expressas no Documento de Aparecida, reconhecemos também que "as atividades fundamentais de uma universidade católica deverão vincular-se e harmonizar-se com a missão evangelizadora da Igreja” (CELAM, 2007, n. 341). 
Para uma instituição católica, "o empenho em anunciar o Evangelho aos homens do nosso tempo, animados pela esperança, mas ao mesmo tempo torturados muitas vezes pelo medo e pela angústia, é sem dúvida alguma um serviço prestado à comunidade dos cristãos, bem como a toda a humanidade" (PAULO VI, 1982, n. 1). Por essa razão, somos, todos, convidados a refletir sobre como tornar nossas atividades específicas uma forma especial de viver e de difundir o ensinamento cristão do amor, do respeito à dignidade da vida humana, da atenção aos que sofrem, da fraternidade, da justiça social e do compromisso pessoal com a verdade. Esse é, por assim dizer, o sentido subjetivo ou pessoal da evangelização, ou seja, a evangelização que cada um de nós realiza.

Porém, além desse sentido pessoal da evangelização, há um sentido objetivo e institucional, que se refere às ações propriamente voltadas à tarefa de evangelizar "não apenas com relação aos indivíduos, mas também com relação às estruturas do saber científico, na sociedade atual" (CNBB, 1988a, n. 21). A Universidade Católica, assim, como parte da Igreja Católica, deve se empenhar por tornar cada vez mais clara e explícita sua missão institucional, fazendo das ações pastorais que desenvolve seu jeito próprio de evangelizar. Desse modo, contribui para a realização da missão da própria Igreja.

A palavra pastoral, na tradição cristã, faz referência ao "bom pastor", a figura emblemática da parábola de Jesus (cf. Jo 10,1-18). Na atitude do bom pastor de "dar a vida pelas suas ovelhas", como fez Jesus, a Igreja e os cristãos encontram inspiração para agir em conformidade à mensagem do Evangelho. Assim, a Pastoral Universitária tem lugar de destaque na Instituição e não pode ser considerada apenas setor complementar ou serviço adicional. A pastoral na Universidade Católica garante fidelidade à sua missão e, por essa razão, não pode ser considerada como simples apêndice às tantas atividades que a Instituição realiza. Toda a comunidade acadêmica, incluindo dirigentes, professores, colaboradores e estudantes, precisa compreender que a pastoral não é tão somente uma atividade, mas um modo de ser da própria Universidade.

Do ponto de vista histórico, percebe-se que a ação pastoral no âmbito das Universidades é algo recente no Brasil, em razão do retardo com que as Universidades foram instaladas no país, em relação às escolas superiores das outras nações latino-americanas. Apenas para se ter uma idéia desse quadro, citem-se as Universidades de Santo Domingo, fundada em 1538; a do México, em 1551; a da Colômbia, em 1573 e a da Guatemala, em 1662. No Brasil, contudo, depois de algumas escolas superiores isoladas, a primeira universidade 
será erigida apenas em 1931. ${ }^{1}$ Por essa razão, "também a pastoral da Universidade tem pouco tempo de existência" (CNBB, 1988a, p. 42). Nos primórdios da ação evangelizadora da universidade brasileira, devemos recordar a fundação da JUC - Juventude Universitária Católica - , em 1935 (CNBB, 1988a, n. 47). Depois dos acontecimentos dolorosos que se sucederam entre 1964 e 1968, culminando com a extinção da JUC, a Igreja do Brasil não mais trabalhou com a Pastoral Universitária, a não ser por meio das instituições católicas de ensino superior (CNBB, 1988a, n. 56).

\section{Desafios atuais para a evangelização na universidade}

Nos últimos tempos, a Igreja tem acenado, com veemência, para os desafios do mundo atual: a humanidade, afirma o Concílio Ecumênico Vaticano II, vive hoje uma fase nova da sua história, na qual profundas e rápidas transformações se estendem progressivamente a toda a terra. Provocadas pela inteligência e atividade criadora do homem, elas recaem sobre o mesmo homem, sobre os seus juízos e desejos individuais e coletivos, sobre os seus modos de pensar e agir, tanto em relação às coisas como às pessoas. De tal modo que podemos já falar em uma verdadeira transformação social e cultural, que se reflete também na vida religiosa (CONCÍLIO ECUMÊNICO VATICANO II, 1966; GAUDIUM ET SPES, n. 4). O início deste século, de modo especial, é marcado por grandes mudanças em todos os setores e aspectos da sociedade. As influências da pós-modernidade e, mais recentemente, do fenômeno da globalização tem alterado significativamente o modo de vida das pessoas e a forma pela qual compreendem o mundo, conduzindo-as a uma verdadeira crise de civilização, como alertava João Paulo II (JOÃO PAULO II, 1994a, n. 52). É nesta realidade que a Universidade está inserida, consciente de que é preciso "evangelizar a modernidade" (CNBB, 1988a, n. 268). Nesse contexto, também a experiência religiosa (a vivência de fé de cada um, sua forma de compreender

Trata-se da Universidade do Brasil, no Rio de Janeiro. CNBB. Evangelização e pastoral da universidade. São Paulo: Paulinas, 1988. p. 24-25. Alguns consideram que a primeira universidade brasileira, verdadeira em todos os sentidos, é a Universidade de São Paulo, USP, fundada em 1934. 
e de se relacionar com o Transcendente) sofre os influxos dos desafios que se apresentam. Mais do que reagir impulsivamente a esses desafios ou evitá-los, é preciso refletir sobre eles e tomar posição consciente, contribuindo assim para o diálogo sincero e aberto entre as novas expressões culturais e a tradição cristã. Pode também promover o diálogo com as diferentes ciências, os intelectuais, o mundo das artes, a política, o setor dos negócios, os organismos do terceiro setor, entre outros. Eis alguns dos traços peculiares de nosso tempo que se apresentam como desafios à evangelização:

a) o fenômeno da fragmentação: percebe-se um processo de fragmentação em muitos campos da cultura e do saber: na família, nos padrões de relacionamento, na ética e na política, na educação, nas ciências e nas artes, no pensamento filosófico e teológico, na compreensão do sentido da vida, no modo de entender a presença humana no mundo e na história, etc. Tal fragmentação implica a passagem de uma visão mais ou menos unificada da vida para um olhar multirreferencial, a partir do qual também os valores éticos e as normas morais são vistos sob novo enfoque. E na construção da visão do todo há o desafio de se identificar o que é essencial à vida humana. Precisamos aprender a reconhecer que, "se não existe o dom da unidade no Espírito Santo, a fragmentação da humanidade é inevitável" (BENTO XVI, 2006);

b) o enfraquecimento das utopias: utopias como o socialismo real e o comunismo, que prometiam um mundo de igualdade e justiça, fracassaram. A derrocada das ditaduras socialistas e as dificuldades socioeconômicas decorrentes causaram profunda decepção em todos quantos alimentavam a ilusão da absoluta igualdade social e econômica. Por outro lado, o neoliberalismo e o capitalismo financeiro seguem mantendo, ou aprofundando, a condição de exclusão e marginalização de enormes contingentes humanos em todos os países, principalmente aqueles que ocupam a periferia do sistema produtivo. Deve-se considerar o desafio - ao levar às pessoas a sempre atual esperança da mensagem cristã - de que atualmente vivemos num contexto onde, por vezes, surgem situações que geram desilusão e desesperança, e onde o sentido mesmo da vida parece se perder;

c) a rejeição dos grandes relatos: o mundo ocidental se habituou a uma estrutura racionalista que dava unidade a todo o pensamento, sob a forma de um único relato que explicasse todas as coisas por meio de uma espécie de teoria geral. Hoje, contudo, está em curso um processo de fragmentação na 
cultura, nas ciências e na Filosofia, dando fim à unidade antes percebida. $\mathrm{O}$ subjetivismo (ou seja, a tendência negativa de priorizar apenas os aspectos subjetivos) tomou conta do pensamento ocidental, permitindo o florescimento do relativismo, que atinge também o campo da ética: tudo parece ser relativo, também o bem e o mal, a verdade e o erro (GERVILLA, 1993). É um desafio, para a evangelização da universidade católica, favorecer a reflexão madura sobre a unidade na diversidade, tendo como critério a busca de fundamentos válidos e permanentes;

d) busca de significado para a existência: a vida humana, diante dos novos paradigmas culturais, parece ter mudado profundamente seu significado. A ausência de um sentido maior para a vida pode tornar a pessoa vítima de si mesma, encerrando sua existência no aqui e agora, sem referência a uma dimensão que ultrapassa a própria experiência pessoal. Para além do ter, do prazer, do poder e do fazer, as pessoas precisam descobrir a necessidade de ser e de se abrir à Transcendência. Gradativamente, sobretudo com os avanços das tecnologias, a comunicação tornou-se veloz, eficiente, as relações se multiplicaram, o mercado ganhou velocidade, tudo foi acelerado. Cada vez mais as decisões foram migrando da instituição para a pessoa, do objetivo para o subjetivo. Sobretudo no Ocidente, cada vez mais a moral foi sendo fruto de decisões individuais, ao invés de grandes tradições culturais ou religiosas. De fato, vive-se um momento no qual parece que o subjetivismo impera;

e) crise do humanismo: o valor do ser humano, sua natureza própria e sua dignidade, muitas vezes também ficam diminuídos e fragmentados. As pessoas também foram instrumentalizadas, deixando de ser fim e tornando-se apenas meio para outras finalidades práticas (como a produção, o crescimento econômico, o desenvolvimento material, etc). Diante de tantas concepções, quer científicas, antropológicas, filosóficas e teológicas, a própria identidade humana ficou diluída. Esse é o paradoxo que hoje se nos apresenta, como afirma Martin Heidegger: "nenhuma época acumulou conhecimentos tão numerosos sobre o homem [...] Mas também nenhuma época soube menos o que é o homem" (HEIDEGGER, 1953, p. 266). A tendência atual, ao dar ênfase aos aspectos materiais da vida, não apenas mata a dimensão religiosa da existência, mas destrói o que é próprio do ser humano: a sua capacidade de transcender. A falta de significado para a vida humana, incluindo a ausência de sentido para a dimensão da transcendência, conduziu as pessoas a estabelecerem relacionamentos em que prevalecem os interesses individuais. 
Para reverter este quadro e dar sua contribuição efetiva, destaca-se como desafio para a Universidade Católica oferecer aos seus estudantes a oportunidade de formação para a solidariedade e para a sensibilidade social e ambiental. É preciso criar espaços para "desenvolver em conjunto a reflexão sobre o novo humanismo, tendo em conta os grandes desafios da época contemporânea e procurando unir a fé e a cultura de maneira harmoniosa" (BENTO XVI, 2005).

\section{A experiência de fé no contexto atual}

Contudo, ao lado destes aspectos, surgem questões específicas do âmbito das religiões e da espiritualidade. Ignorá-los significaria desconsiderar as relações que, de alguma forma, dizem respeito à dimensão, no ser humano, de busca do Transcendente, à dimensão do mistério da vida. A Universidade Católica deve desenvolver e cultivar um interesse sadio pelas causas dos fenômenos religiosos de nosso tempo, apreciando de modo crítico também os contrastes, que levam os indivíduos do fanatismo ao ateísmo prático ou militante.

a) Retorno ao sagrado. Vivemos num mundo "secularizado e, apesar disso, fascinado pela busca do sagrado" (JOÃO PAULO II, 1999, n. 46). Ao lado desses fenômenos de transformação de nosso tempo, percebe-se, entretanto, um movimento de volta ao sagrado e de busca da transcendência, marcado pela explosão de novas formas de religiosidade. Um dos motivos desse fenômeno pode ser a reação cultural diante do racionalismo moderno (a supervalorização da razão em detrimento das outras dimensões da vida humana). Também há uma forte tendência de cada pessoa buscar sua própria expressão religiosa num subjetivismo que respeita os interesses pessoais e, em algumas situações, numa nova forma de unidade holística, isto é, integral e de totalidade.

b) $\mathrm{O}$ risco dos fundamentalismos. $\mathrm{O}$ retorno ao religioso abriu espaço também para posturas fundamentalistas e messiânicas. Tais posturas, por vezes fundadas em princípios radicais e inflexíveis, veem o mundo somente pela ótica da religião, excluindo outras formas de entendimento e interpretação da realidade. Esses reducionismos não podem ocupar espaço na Universidade, exatamente porque ela não pode se deixar influenciar nem por ideologias materialistas, nem por concepções religiosas avessas à constante busca da 
verdade e fechadas ao diálogo. Com razão, "a Igreja também não fecha os olhos diante do perigo do fanatismo, ou fundamentalismo, daqueles que, em nome de uma ideologia que se pretende científica ou religiosa, defendem poder impor aos outros homens a sua concepção da verdade e do bem" (JOÃO PAULO II, 1991, n. 46). Por isso, para a Universidade Católica, a evangelização tem como desafio a superação das formas de proselitismo (a simples conquista de novos adeptos), de modo a não excluir quem professa outra fé ou mesmo aqueles que afirmam não crer; devemos sempre nos perguntar: "em que creem aqueles que não creem?" (ECO; MARTINI, 2000). A atitude de abertura a todos e de diálogo fraterno, na busca comum de sentido para a vida, deve caracterizar o nosso jeito próprio de evangelizar.

c) O risco do superficialismo religioso. Nesse contexto de diversidade religiosa, a experiência da fé cristã tornou-se uma opção a mais no cabedal de alternativas místicas da pós-modernidade. Além disso, a pessoa de Jesus Cristo é apresentada de diversas formas. As opiniões variam entre um "Deus que se fez homem", um "grande guru", ou mesmo um "sujeito interessante", como a ele alguns se referem. A Igreja Católica, fundada sob a inspiração cristã, também passa por uma série de críticas e de questionamentos. A própria tradição teológica é contestada pelas teorias progressistas, como a Teologia Política, a Teologia do Conflito, a Teologia Feminista, entre outras expressões. Os dogmas católicos também se tornaram objeto de crítica e contestação. A Bíblia também passou a ser questionada. Nos últimos anos, ela foi pesquisada e interpretada por um grande número de pessoas oriundas das mais diversas ciências (arqueologia, antropologia, história, etc). Para muitos, trata-se de um "livro sagrado" a ser seguido ao pé da letra. Para outros, ela é a expressão da Palavra de Deus a inspirar a construção da comunidade de fé e de um mundo melhor. Para outros, contudo, não passa de um simples documento histórico ou uma obra literária.

Neste sentido, constitui-se grande desafio para a evangelização na Universidade o estabelecimento de meios para que as pessoas redescubram o lugar do sagrado no mundo e em suas vidas. A Instituição Católica tem um papel decisivo na formação também religiosa das novas gerações, sobretudo no que diz respeito ao senso crítico diante do amplo leque de manifestações religiosas de nosso tempo. 


\section{Os conceitos de evangelização e de pastoral}

Os conceitos de evangelização e pastoral estão intimamente ligados. Em termos teológicos, a pastoral é a ação evangelizadora organizada da Igreja no mundo. Esta definição engloba cinco categorias que precisam ser bem compreendidas:

a) a ação: em primeiro lugar, pastoral é práxis, ou seja, uma ação fundamentada em princípios claros. Pastoral é uma práxis cristã para responder aos apelos da realidade na vida das pessoas e nos contextos vitais das instituições. Ela é a interrelação do pastor com o rebanho. Para fazer pastoral, portanto, é preciso ir ao campo e "Chamar as ovelhas pelo nome, conduzir às pastagens, ir à frente das ovelhas [...].”² $\mathrm{Na}$ Universidade Católica, é preciso fazer da pastoral uma ação que se inspire no único e verdadeiro Pastor, o próprio Jesus Cristo, que se compadecia das pessoas sem orientação e sem sentido para a vida, que viviam como "ovelhas sem pastor";

b) a evangelização: o termo evangelização não é unívoco. $\mathrm{Na}$ exortação apostólica Evangelii Nuntiandi, do Papa Paulo VI, o conceito tem um sentido bastante amplo. Ali se afirma que a Igreja existe para evangelizar, ou seja, para anunciar e ensinar, ser canal e o dom da graça divina, reconciliar os pecadores com Deus, perpetuar a Eucaristia (PAULO VI, 1982, n. 14). A evangelização é, portanto, uma realidade rica, complexa e dinâmica que requer: o testemunho de vida; o anúncio explícito; a adesão do coração; a inserção na comunidade; o acolhimento dos sinais e dos sacramentos; a transformação e a renovação da humanidade (CNBB, 1986). A tarefa de evangelizar da Universidade Católica é consequência direta da própria condição católica da instituição;

c) a organização: o conceito de organização refere-se a um trabalho sistematizado, com planejamento, objetivos e metodologia. Isso exige clareza de conceitos, planejamento participativo, capacidade de gerenciamento de conflitos, legitimidade e carisma da coordenação. Para coordenar uma ação organizada, com caráter pastoral, não basta somente uma atitude irrepreensível, nem poder institucional ou preparo técnico. É preciso carisma, no sentido teológico do termo:

2 Para caracterizar melhor a ação do pastor, cf., entre outras, as seguintes passagens bíblicas: Ez 37, S1 22 e Jo 10. 
dom e santidade, isto é, a graça de Deus que nos torna capazes de "viver segundo o Espírito de Deus" e não apenas "segundo a carne". A organização pastoral, na Universidade Católica, deve também levar em conta as peculiaridades do universo acadêmico, utilizando-se de linguagem e metodologia adequadas a fim de sensibilizar e comprometer os jovens educandos;

d) a eclesialidade: a Igreja é entendida, a partir do Concílio Vaticano II, como Povo de Deus, comunidade dos cristãos católicos (religiosos e leigos), servidora da humanidade e iluminada pela mensagem do Evangelho. Como rebanho de Cristo, a Igreja é guiada por seus pastores (os diáconos, os padres e os bispos). Nesse sentido, a Igreja é um instrumento a serviço da construção do Reino de Deus. Por essa razão, ela muda seu modo de agir na história e nas culturas diversas, tornando-se cada vez mais atenta aos "sinais dos tempos", sem, contudo, perder a riqueza de seus valores fundamentais e perenes;

e) o mundo: mundo é aquilo que se nos apresenta, a realidade como um todo, o entorno natural, histórico e humano, o aspecto fenomenológico (aquilo que se manifesta), o conjunto das realidades que nos rodeiam. A evangelização não é uma ação desvinculada do mundo, mas se dirige às pessoas inseridas em seus contextos próprios de vida. Assim, a evangelização precisa atender aos apelos da realidade e estar atenta ao mundo que a cerca.

O aspecto específico da ação evangelizadora da Universidade Católica é o diálogo entre a fé, cultura, ciência e vida. A evangelização no ambiente universitário precisa alargar ao máximo os horizontes, ao ponto de dialogar com o que existe de mais significativo e universal no mundo do conhecimento. $\mathrm{O}$ avanço da ciência trouxe grandes desafios à Universidade, principalmente no campo da Ética e, especificamente, da Bioética. Esses desafios emergentes, para os quais a Igreja se empenha em formular respostas claras a partir de seus fundamentos doutrinais, apontam para a necessidade de um estreitamento nas relações e propósitos entre a Universidade e a Igreja. Desse modo, a Universidade Católica poderá não somente ser fiel e educada pela Igreja, mas também educar a própria Igreja, contribuindo para que esta também seja sempre fiel ao Evangelho de Jesus Cristo aplicado à cultura contemporânea. Também a Unesco reconhece o papel específico da Universidade no contexto cultural, quando afirma: "a universalidade do Ensino Superior exige: que este tenha um papel ético e de orientação em período de crise de valores. Que ele desenvolva, por meio de suas atividades, uma cultura da paz. Que este tenha por vocação não somente formar, mas educar" (UNESCO, 1998, p. 124). 


\section{Universidade e evangelização}

A Universidade é um lugar muito específico na sociedade, e a Universidade Católica o é ainda mais. Cada ambiente específico precisa de projetos distintos na esfera da evangelização. O que a Igreja espera da Universidade Católica? Para a Igreja, a instituição católica de ensino superior deve: a) formar profissionais competentes (ensino); b) conservar o saber acumulado e fazer progredir o conhecimento (pesquisa); c) colocar-se a serviço da comunidade em que se encontra e da comunidade nacional (extensão); d) formar pessoas comprometidas com o bem, a verdade e a justiça (formação integral); e) ajudar os membros da comunidade educativa a aprofundarem seu conhecimento e experiência da fé (pastoral) (CNBB, 1992, p. 80). Aí, encontramos uma síntese modelar da missão da Universidade Católica, contemplando todas as dimensões da tarefa de educar no ensino superior, bem como aquilo que é próprio da missão evangelizadora da Igreja e da Universidade.

A evangelização, na Universidade Católica, deverá mostrar a imagem cristã da pessoa humana e do mundo. Não são apenas os projetos específicos de pastoral que vão concretizar tal tarefa. É a Universidade inteira, seus gestores, seus professores e colaboradores, sua cultura, seu modo de ser e de fazer que deve transparecer tal concepção. Não se trata apenas de falar do Evangelho, mas, sobretudo, de testemunhá-lo na vida. A missão de evangelizar na Universidade Católica, portanto, não deve ser algo em paralelo à própria vida acadêmica. Pelo contrário, a evangelização deve tomar vulto e alavancar uma "cultura institucional de evangelização", o que poderia ser resumido na expressão "Universidade em pastoral". ${ }^{3}$ De fato, é preciso reconhecer que "a prática evangelizadora deve ser sempre processo que integra fé e vida, em nível social e pessoal, e, por outro lado, a prática educativa autêntica carrega sempre em si dimensões e valores da boa nova do Reino" (CNBB, 1992, n. 89). No caso específico da pastoral no ambiente universitário, é preciso distinguir, ainda, os conceitos de Pastoral Universitária (PU) e Pastoral da Universidade (PdU): a diferença básica entre a PU e a PdU é de onde parte a iniciativa de fazer a

A expressão "Universidade em Pastoral” foi cunhada em setembro de 1987, em Campinas, num encontro nacional da Pastoral Universitária e de Instituições de Ensino Superior Católicas. ALVES, Vicente Paulo. Universidade em pastoral: uma nova visão sobre o jeito convencional de fazer pastoral na universidade. Petrópolis, RJ: Vozes, 2002. 
pastoral; enquanto na PU a iniciativa é dos próprios alunos (apoiados pela estrutura diocesana ou paroquial), na PdU a iniciativa é da própria universidade que cria um setor responsável pela animação da pastoral em seu próprio âmbito de atuação (ALVES, 2002, p. 8).

A chave para a compreensão aprofundada da missão evangelizadora da Universidade Católica está em sua própria natureza específica, o que significa reconhecer sua identidade cristã e católica. Em primeiro lugar, a natureza confessional da Universidade Católica inspira e orienta sua existência, fazendoa se conformar cada vez mais aos valores cristãos e transformando sua ação num verdadeiro testemunho evangélico, como "sal da terra e luz do mundo" (Mt 5,13-16). Em segundo lugar, a Universidade Católica é também guiada pelas orientações do magistério da Igreja e inserida plenamente na vida eclesial. Isso significa que suas ações não são iniciativas isoladas, mas um empenho que se soma à mesma missão da Igreja e ao mesmo compromisso de servir ao bem da humanidade. Disso decorre a fidelidade à doutrina e aos ensinamentos da Igreja e, ao mesmo tempo, ao espírito de unidade em relação à ação evangelizadora desenvolvida em cada Igreja particular (isto é, em cada diocese) em que nossas obras estão inseridas. Por isso, estamos em consonância com as exigências da evangelização propostas pela Igreja: anúncio, diálogo, testemunho e serviço, conscientes de que "A missão da Igreja é uma só. As tarefas que decorrem da missão são muitas" (CNBB, 1988b, n. 67).

Conforme a orientação da Igreja, algumas condições são indispensáveis para a Universidade ser reconhecida como instituição Católica: ter um corpo docente com idoneidade científica e pedagógica, integridade de doutrina e probidade de vida; ter uma faculdade ou uma disciplina de Teologia; oferecer cuidado pastoral aos estudantes (SANTA SÉ, [1983] 2002, can. 810, 811 e 813). Desse modo, a inspiração cristã na Universidade Católica impõelhe incluir a dimensão ética e religiosa nas atividades de ensino e pesquisa e avaliar as conquistas da ciência e da técnica na perspectiva da totalidade humana (JOÃO PAULO II, 1994b, n. 7). Cabe, portanto, particularmente à Universidade Católica fazer aquilo que não é feito em outros ambientes eclesiais: produzir conhecimento, em todas as áreas da ciência, em profundo diálogo com a fé cristã. Essa é a síntese da missão evangelizadora da Universidade, seu jeito próprio de anunciar a mensagem cristã. A Universidade Católica é o lugar privilegiado do diálogo entre a fé e a razão (JOÃO PAULO II, 1998), a partir da compreensão de que a fé, sem a razão, pode levar ao 
fanatismo e à dominação; e a razão, sem a fé, pode conduzir ao materialismo ou ao tecnicismo. Ambas as situações são contrárias ao humanismo e, portanto, avessas ao projeto de Deus. O diálogo entre a fé e a razão está a serviço de uma visão integral da pessoa e de sua plena humanização.

A Universidade Católica precisa entender a evangelização num sentido amplo. A evangelização deverá permear os vários níveis da vida acadêmica: a cultura e a ciência, a dimensão social, a formação humana e profissional, os aspectos propriamente teológicos (a espiritualidade, a ação iluminada pela fé) e a própria administração da Universidade. De modo geral, a missão da Universidade Católica é de colaborar com a sociedade na formação de pessoas justas, éticas, livres e solidárias. Seu compromisso é formar bons cidadãos e competentes profissionais. No entanto, na condição de instituição pontifícia, católica e marista, tem também a responsabilidade de promover a cultura da vida com base no Evangelho de Jesus Cristo.

$\mathrm{Na}$ prática, isso significa o estabelecimento de pontes entre o conhecimento produzido em geral e os valores cristãos. Isso não significa limitação de horizontes ou cerceamento de liberdade, mas, pelo contrário, diz respeito ao fortalecimento da flexibilidade da dimensão ética, capaz de dialogar com qualquer sistema cultural, uma vez que os critérios de defesa e promoção da vida são salvaguardados. A fidelidade da Universidade Católica ao Evangelho exige dela mesma a capacidade de identificar e ser fiel aos valores do Reino de Deus, do Evangelho e, ao mesmo tempo, abertura ao diálogo, flexibilidade de linguagem com todos os setores da sociedade com o objetivo de promover a vida integralmente. De fato, Jesus afirmou que veio para trazer a vida em abundância e plenitude (Jo 10,10).

\section{Evangelização dos saberes}

O estabelecimento de pontos entre o conhecimento produzido em geral e a fé exige da Universidade Católica a superação de visões parciais. Deve-se lutar contra as ideologias, a tendência ao cientificismo, o racionalismo absolutista, o pragmatismo, o espiritualismo, entre outras tendências e modismos intelectuais. Isso não quer dizer que se devem fechar as portas à discussão intelectual. Muito pelo contrário, é preciso promovê-la. Na Universidade, pois, se encontra de maneira concentrada a intelectualidade da sociedade, com seu universo de idéias, conceitos 
e teorias. Esse universo também precisa de espaço para o diálogo e de cuidado pastoral num sentido renovado. O mundo da Universidade não é, em definitivo, um mundo agrário e pastoril. As "ovelhas" que precisam ser "pastoreadas" no universo acadêmico, além das próprias pessoas, são as idéias e as doutrinas, as concepções de mundo, que muitas vezes seguem sem bússola por caminhos incertos. Aqui está uma função própria da Universidade Católica: tornar-se um fórum permanente que consiga discutir, numa perspectiva humanista e cristã, os limites e alcances do conhecimento humano nas mais variadas áreas da ciência. Com efeito, "no serviço à sociedade o interlocutor privilegiado será naturalmente o mundo acadêmico, cultural e científico da região em que atua a Universidade Católica" (JOÃO PAULO II, 1994b, n. 37).

Numa sociedade em que a ciência e a técnica atingiram um grau inédito de autonomia, não raro voltando-se contra o próprio ser humano, a Universidade Católica, de acordo com a sua inspiração evangélica, tem por missão construir um conhecimento que possa ser colocado a serviço do humanismo cristão. É preciso, portanto, com criatividade e audácia, "evangelizar os saberes" para re-humanizar o mundo, re-encantar o ensino e re-criar o planeta. Este é o grande desafio, a missão especial da Universidade Católica: contribuir para que as experiências da fé e da racionalidade se entrecruzem e se fecundem mutuamente, produzindo frutos de amor e justiça, de verdade e de solidariedade no mundo e na Igreja.

\section{Evangelização e espiritualidade}

A espiritualidade é, como a própria palavra sugere, viver segundo o espírito e não apenas segundo a nossa condição biológica e material. Não se trata de estabelecer separação entre matéria e espírito, mas é um aceno àquilo que está na raiz da experiência humana: sua natureza material em busca de transcendência. Assim, a espiritualidade, como força que nos move e anima (anima, em latim, quer dizer alma), nos faz superar a imanência (aquilo que nos prende ao mundo, à materialidade da vida) para chegarmos à transcendência (a dimensão espiritual do humano).

A Pastoral Universitária deverá contribuir para que a espiritualidade seja celebrada. As celebrações, os ritos e as liturgias (os sacramentos, incluindo a Missa, as orações e bênçãos, etc.), em todas as religiões, são o ponto de chegada do processo de vivência das diversas expressões de espiritualidade. Sem essa 
dimensão que "vem de dentro", as celebrações não passam de rituais vazios e mecânicos, sem sentido ou significado para a vida. É como dar um beijo em quem não se ama. Quando a espiritualidade ainda não está presente na vida da Universidade, qualquer celebração corre o risco de ser algo alheio ao contexto vital, como um teatro, uma simples representação, distante da vida. Torna-se uma tarefa a ser cumprida, algo pontual no calendário da instituição, mas que não reflete a interioridade das pessoas.

As celebrações somente serão significativas quando acompanhadas da vivência espiritual dos que a celebram. O desafio está em fazer dos momentos de celebração uma forma de viver o cotidiano acadêmico sob a inspiração do Espírito de Deus. Então, as celebrações serão realmente significativas para a comunidade acadêmica, sem necessidade de motivações externas. A Universidade Católica precisa encontrar meios adequados para alimentar a espiritualidade a fim de, a partir disso, promover momentos fortes de celebração, quer no tempo litúrgico da Igreja, quer nos momentos específicos da própria vida da Instituição. É nessa concepção que toma lugar o importante papel da Paróquia Universitária e de ações organizadas de pastoral. Trataremos da Paróquia Universitária e das ações específicas de articulação da pastoral mais à frente.

Ainda no âmbito da espiritualidade, vale destacar que as iniciativas não podem perder de vista o objetivo fundamental de ajudar as pessoas a despertar ou aprofundar sua experiência de fé vivida no dia-a-dia. De modo geral, as pessoas parecem descrentes em relação aos discursos: elas creem mais nas atitudes e na vivência pessoal. Como se costuma dizer, "as palavras comovem; os exemplos arrastam". A experiência cristã não se esgota numa doutrina, mas tem seu centro na experiência pessoal e comunitária de encontro com a pessoa de Jesus Cristo. Portanto, o nosso jeito próprio de evangelizar deve ajudar as pessoas a migrarem de uma experiência religiosa demasiadamente conceitual para uma religiosidade que se apóie na própria vida.

A verdade cristã não é apenas um problema teórico, mas uma questão de vida, de atitude iluminada por um ideal. Conhecer Jesus Cristo não é uma simples questão de "saber" quem ele é, mas de seguir seus ensinamentos. O Cristianismo, portanto, é uma experiência, proposta de vida, atitude de abrir-se aos outros e de anunciar a mensagem de Jesus que não veio para condenar o mundo, mas para revelar o amor misericordioso de Deus, como mostra a parábola do filho pródigo (Lc 15,11-31). A experiência de fé, portanto, ainda 
que celebrada e traduzida em oração, tem a ver com as relações e as estruturas do mundo objetivo, com a vida concreta das pessoas, com suas preocupações e ansiedades, com suas necessidades e seus sonhos.

Para os cristãos, Jesus Cristo se fez humano não para si, mas para o outro e afirma que o maior é aquele que serve (Mc 10,44), sem fechar-se em si mesmo. Essa é a mais genuína espiritualidade cristã: colocar-se a serviço da vida, do bem e do amor. É isso que devemos mostrar nas salas de aula e laboratórios, nos quartos de hospital, nos estúdios de comunicação onde atuamos. Não apenas com discursos e conceitos, mas pelas atitudes e pela vida.

Isso pode se aplicar a todas as áreas do conhecimento. Numa universidade católica, todas as atividades, em todos os setores, podem se voltar à evangelização. Não é somente com discursos teológicos que se anuncia a mensagem cristã. Também os discursos são importantes, mas não devem prescindir da experiência de vida e das oportunidades do cotidiano acadêmico. Contudo, quando os discursos se fizerem necessários, eles devem estar em conformidade com a pedagogia de Jesus: em linguagem simples, de acordo com o contexto e a realidade de seus ouvintes, sem agredir nem impor. A experiência religiosa deve ser iluminada pela razão, pela busca dos fundamentos, e que o estudo e a busca da verdade possam ser iluminados pela fé. Não podemos separar a razão e a fé.

\section{Evangelização e ação transformadora no mundo}

No cerne da experiência cristã está o convite de Jesus não para simplesmente conhecê-lo, mas para segui-lo. Isso significa viver como ele viveu: dedicar-se à construção de um mundo melhor para todos, o que para ele correspondia à expressão Reino de Deus. Neste sentido, a Universidade Católica, além do anúncio da mensagem cristã e da reflexão sobre os dados da fé, tem a responsabilidade de traduzir em atitudes e ações concretas a fé que cultiva, desenvolvendo uma verdadeira "pedagogia do anúncio" (CNBB, 1988a, n. 70). A partir disso, se pode compreender a pastoral universitária como:

presença ativa da Igreja na Universidade, por meio de grupos de alunos que trabalham na evangelização da própria Universidade, pretendendo, entre outros objetivos, transformá-la de instrumento de dominação e de privilégio, em instrumento do Reino de Deus e, portanto, de justiça e de serviço. (CNBB, 1988a, n. 63). 
Portanto, além do diálogo entre cultura e fé e de uma espiritualidade fecunda, a Universidade Católica não poderá se furtar a um compromisso solidário efetivo, de forma institucionalizada, a partir de um projeto sistemático de solidariedade e de promoção social e humana. Não se trata de uma opção entre outras, mas da opção fundamental que está no coração da mensagem cristã: "O que fizeres a estes meus irmãos mais pequeninos, a mim o fareis", é o que declara Jesus (Mt 25, 1ss). A Constituição Apostólica Ex Corde Ecclesiae, afirma de modo explícito a responsabilidade das instituições católicas de ensino superior em relação à promoção social: "o espírito cristão de serviço aos outros para a promoção da justiça social reveste particular importância para cada Universidade Católica"; e ainda: "cada Universidade Católica deve sentir a responsabilidade de contribuir concretamente para o progresso da sociedade na qual trabalha" (JOÃO PAULO II, 1994b, n. 34). Desse modo, afinada com os valores cristãos, que seus educandos deverão herdar, a Universidade Católica deverá imprimir uma marca ética e solidária no coração de cada um, e isso é o seu maior legado. Para tanto, é imprescindível um testemunho do amor cristão e dos valores cristãos de modo institucional, permanente e processual.

De modo especial, somos chamados a dar atenção particular aos que mais necessitam. Todos os que se ocupam com a pastoral universitária, conforme exortação de João Paulo II, devem ajudar os professores e alunos a serem mais conscientes da sua responsabilidade em relação aos que sofrem física e espiritualmente. Segundo o exemplo de Cristo, devem estar particularmente atentos aos mais pobres e a quem sofre injustiça no campo econômico, social, cultural e religioso, na comunidade acadêmica e também fora dela (JOÃO PAULO II, 1994b, n. 40). Decorrência natural dessa situação será o aproveitamento, por parte das pessoas que trabalham na Pastoral, das oportunidades de trabalho social existentes na Instituição para os propósitos de Evangelização.

\section{As expressões pastorais num complexo universitário}

Como se tem refletido até aqui, a dimensão pastoral, na Universidade Católica, não está simplesmente restrita a "ações ou eventos religiosos", que compreendem as liturgias, as celebrações, os retiros, os encontros de reflexão e espiritualidade. Embora isso também seja importante e deva acontecer como expressão da fé cristã vivida e professada pela Universidade, não se pode parar 
aí. A ação pastoral acontece também, e de modo muito especial, nas ações cotidianas próprias da Universidade. A Instituição deve empenhar-se em ser uma comunidade na qual o Cristianismo constitui-se como fonte inspiradora. Desse modo, a pastoral não se restringe a um setor específico, mas, antes, corresponde a uma Universidade inteira em pastoral, da sala de aula à administração. Cada um a seu modo, em seu setor de trabalho, nas especificidades de suas tarefas. Os administradores, os professores, os funcionários e, representando o maior contingente, os estudantes, devem considerar-se co-responsáveis pela missão institucional de educar para a vida, de evangelizar, sobretudo, o mundo da cultura e da educação.

Aos professores também cabe a responsabilidade pastoral da Universidade, na medida em que inserem sua ação docente numa perspectiva de fé. Assim, o professor assume um compromisso ao mesmo tempo educativo e de fé, que transcende os próprios limites da sala de aula e dos espaços pedagógicos propriamente ditos. Em que condições o professor pode contribuir concretamente para a ação pastoral? Ao mostrar aos seus estudantes uma atitude de abertura ao Transcendente, evitando cair num puro materialismo cientificista; ao demonstrar aos seus estudantes o valor da solidariedade e do empenho humano em construir comunidades fraternas; ao ensinar o valor do respeito à vida e à dignidade das pessoas; ao tratar seus alunos e colegas com amor; ao mostrar que o perdão vale mais do que a vingança; ao ensinar que o ser vale mais do que o ter, o poder e o prazer.

Aos outros colaboradores também cabe a ação pastoral, naquilo que é próprio de suas tarefas, mas, sobretudo, a partir de algumas atitudes fundamentais: a atenção dada às pessoas; a justiça nas relações de trabalho; a preocupação com os que mais precisam de apoio; a postura ética assumida como meio igualmente fecundo de educação para a vida, sobretudo pelo testemunho cotidiano e muitas vezes silencioso.

Aos estudantes cabe, igualmente, a missão de assumir com responsabilidade os seus estudos, abrindo-se também à formação integral do ser humano em suas dimensões social, biológica, espiritual, além da técnica e profissional. Como sujeitos de sua própria formação, os estudantes devem, auxiliados pelos educadores, traçar itinerários para a vida, considerando o diálogo, o respeito, a dignidade humana, a sensibilidade, a generosidade, em vista da construção de um mundo melhor. São eles o centro de atenção do carisma marista (INSTITUTO MARISTA, 2003, n. 53), a razão maior de existir da universidade e a maior esperança para a concretização da missão da universidade católica no mundo. 
Nesse sentido, uma ação pastoral na Universidade é decorrente da maneira de ser da instituição, da sua missão, do sentido último da sua existência. Algumas instâncias específicas da Universidade, formadas por membros variados da comunidade acadêmica, são referenciais para o desenvolvimento de ações estratégicas em vista do fortalecimento da missão institucional, também no que diz respeito à tarefa de evangelizar. Analisemos tais instâncias:

a) os colegiados: é nos colegiados da Universidade e dos cursos que se definem e se operacionalizam prioridades, concepções e ações. Se a dimensão pastoral atingir os colegiados, todas as decisões neles tomadas poderão refletirse em ações de evangelização. Como já refletimos, a evangelização é anúncio e vivência de uma novidade que aponte ao destino último do ser humano e do mundo. Os colegiados, em função da identidade da Universidade Católica, deverão ser promotores de uma educação que supere a simples instrução e que aponte para a dimensão Transcendente da vida;

b) a administração universitária: os gestores, por força dos cargos que ocupam, devem ser também, e principalmente eles, comprometidos com a missão institucional. Nos mais diversos setores da Universidade, uma vez alimentados pela espiritualidade cristã e pelo carisma marista, eles podem ser autênticos líderes em seus ambientes. Cada gestor pode resgatar o encantamento, cujo pressuposto é a missão de cada um no mundo, e também a missão da instituição. Em sua atuação diária, nos contatos com os estudantes e os colaboradores da instituição, na escolha de prioridades e na atuação junto aos colegiados, os gestores podem contribuir sobremaneira para que a ação pastoral da Universidade seja cada vez mais assumida como tarefa e responsabilidade de todos. Deve-se ressaltar, também, que a pastoral da estrutura da Universidade, ou seja, a evangelização do ambiente de trabalho e da própria organização institucional depende dos gestores e de suas equipes de trabalho. Então, a Universidade toda pode ser um instrumento eficaz de construção da sociedade mais humana para a qual o Evangelho aponta;

c) os centros acadêmicos: os centros acadêmicos tem vida própria, autonomia política e plena liberdade associativa. Essas prerrogativas não são antagônicas com a verdade e a grandeza da missão institucional da Universidade Católica, mas a reforçam. É nos centros acadêmicos que aflora o que de mais específico existe na fenomenologia da juventude: o sadio inconformismo, a abertura para o novo, a utopia, a autenticidade, o sentimento de pertença dos 
jovens universitários. Entretanto, por carência de grandes causas, os centros acadêmicos correm o risco de tornarem-se ambientes de alienação, conduzindo os estudantes a expressões com pouco ou nenhum sentido para a formação profissional e para a vida. A ação pastoral na Universidade deverá atingir o coração dos centros acadêmicos e incluir os estudantes no empenho por uma causa maior do que os interesses particulares de cada curso específico. Os agentes de pastoral deverão ser provocadores de entusiasmo na juventude universitária, para que os jovens se tornem forjadores de esperança e artífices de um futuro mais humano. O ideal cristão, vivido em profundidade, tem força suficiente para incendiar o coração dos jovens, orientando-os a fazerem de suas vidas algo pelo qual valha a pena viver;

d) os setores de trabalho: para o Cristianismo, o trabalho tem um valor fundamental (JOÃO PAULO II, 1981). Trabalhar é contribuir na obra da criação. É ser co-criador na tarefa de transformar o mundo no paraíso, o lugar sonhado por Deus para seus filhos. O mundo do trabalho, na estrutura universitária, é o espaço próprio para uma pastoral que busque o resgate da dignidade humana do trabalho e a criação de ambientes fraternos e solidários. Uma universidade em pastoral deverá ser capaz de fazer do mundo do trabalho um ambiente mais feliz. Para isso, além da garantia dos direitos trabalhistas constitucionais, a Universidade Católica deverá propor programas de qualificação, retiros espirituais para grupos específicos que queiram aprofundar a dimensão da fé, momentos de partilha e lazer, atenção especial para as famílias, celebrações e comemorações em ocasiões especiais. Cada setor de trabalho da Universidade Católica é convocado a ser ambiente propício no qual se estabelecem sadias relações humanas, espaço para o exercício da generosidade e da fraternidade. Bebendo na fonte do carisma marista, todos os colaboradores são desafiados a amar o trabalho e concebê-lo como meio de evangelização (INSTITUTO MARISTA, 2003, n. 113-116). O esforço pessoal de cada um para o cumprimento de seus deveres, a execução de suas atribuições próprias, o bom serviço prestado aos estudantes e aos demais colaboradores são também meios privilegiados de evangelizar. Tudo depende da consciência com que se vive o ritmo cotidiano das ações; o "para quê" e "para quem" se faz determina o "como" se faz. Aqui vale recordar o ensinamento de Jesus, quando afirma: "Buscai em primeiro lugar o Reino de Deus" (Mt 6,33). Em todos os nossos esforços de trabalho, na PUCPR, outro não pode ser nosso objetivo senão a construção do Reino de Deus, por meio de nossa ação evangelizadora no mundo da educação; 
e) os intelectuais cristãos: é imprescindível que haja, na Universidade Católica, grupos específicos de intelectuais cristãos que reflitam a realidade e sistematizem o conhecimento a partir do pensamento e do humanismo cristãos. A pastoral pode ser um instrumento propício para esse fim. Ela pode agrupar, a partir dos diversos colegiados, professores, mestres e doutores que, motivados pela fé, possam contribuir com a Igreja no diálogo com as diversas ciências, com a Filosofia, com o Direito, entre outras áreas. Os intelectuais cristãos são lâmpadas acesas. O Evangelho diz que uma lâmpada precisa ficar em destaque, no alto, para iluminar todo o ambiente (Mt 5,14). Uma luz não pode ficar escondida. Uma Universidade Católica deve ser, portanto, uma luz a iluminar as pessoas na sua caminhada para a realização humana em plenitude, o que inclui, necessariamente, a abertura para a dimensão Transcendente da existência;

f) o mundo das artes e da cultura: a arte e a cultura são expressões humanas que, de certo modo, mais se aproximam da experiência religiosa. A arte nos ajuda a transcender, a buscar o valor das coisas que não se veem, a procurar o que existe do outro lado da montanha da existência humana. É por essa razão que as expressões religiosas e os rituais sempre são revestidas de arte: seja na escultura e na pintura, na música e na dança, na literatura e na poesia, na dramaturgia e assim por diante.

g) as ações sociais: as várias iniciativas de trabalhos sóciocomunitários das Universidades Católicas correspondem ao ensinamento social da Igreja, expresso em diversas encíclicas do papado ao longo dos séculos XIX e XX e, na América Latina, em especial, nas reuniões gerais do episcopado, realizadas em Medellín, Puebla, Santo Domingo e Aparecida. Em todos esses documentos e encontros eclesiais se afirma a necessidade de que todos façam a evangélica opção preferencial pelos pobres. Não se trata apenas de uma opção a mais, mas da opção fundamental, a exemplo de Jesus que privilegiou, em sua ação pastoral, o serviço aos mais necessitados no corpo e no espírito. É preciso mais do que competência técnica para a eficácia do voluntariado. No Evangelho, Jesus diz aos discípulos: sem mim nada podeis fazer (Jo 15,5). A força transformadora de qualquer projeto humano vem da espiritualidade. O voluntariado e a solidariedade, o senso de justiça e a ética, na Universidade Católica, precisam se sustentar numa espiritualidade fecunda, cujos frutos sejam visíveis na vida das pessoas, nas famílias e na sociedade;

h) as atividades acadêmicas: do ponto de vista acadêmico, a Universidade cumpre três funções básicas: o ensino, a pesquisa e a extensão. Numa Instituição Católica, cada uma dessas instâncias também precisa ser 
iluminada pela ação pastoral. No campo do ensino, a pastoral deve contribuir na adoção de uma visão de mundo e da pessoa humana de acordo com os princípios do humanismo cristão. Desse modo, a integração entre fé e razão será não apenas contemplada, mas, sobretudo, incentivada e alimentada. É preciso, portanto, que no campo do ensino se desenvolva uma autêntica pastoral da educação, por meio da qual educadores e educandos poderão inspirar suas vidas e suas práticas educativas e de aprendizagem nos valores do Evangelho. No que diz respeito à pesquisa, a pastoral poderá contribuir para que sejam respeitados os princípios e critérios éticos condizentes com a moral cristã e católica professada pela entidade. A busca da verdade deverá estar sempre em primeiro lugar em qualquer projeto de pesquisa, evitando-se assim que interesses de caráter ideológico possam desvirtuar o sentido próprio das investigações. Também, no campo da pesquisa, é preciso abrir-se a uma verdadeira pastoral da pesquisa, a fim de que os pesquisadores cristãos sejam apoiados em seu empenho de fazer avançar a ciência, sem pôr em risco os princípios éticos que devem reger toda a atividade de investigação científica. No campo da extensão, por fim, a pastoral poderá contribuir para que a Universidade cultive cada vez mais os valores da sensibilidade comunitária, da partilha do conhecimento e da promoção social. Isso virá como decorrência de uma postura institucional que intensifique cada vez mais o caráter comunitário da instituição. Também aqui poderá em muito contribuir uma pastoral social, iluminada pela Palavra de Deus e pela doutrina social da Igreja, de modo a evitar qualquer envolvimento ideológico que poderia corromper o verdadeiro amor à causa da solidariedade;

i) a pastoral da cultura: ocupa lugar de destaque na ação pastoral da PUCPR, a evangelização da cultura, cuja tarefa a Igreja também confia às universidades:

Na perspectiva global de uma pastoral da cultura e dando sempre aos estudantes a formação específica que eles tem o direito de esperar, as universidades, colégios e centros de pesquisa católicos terão a preocupação de assegurar um encontro fecundo entre o Evangelho e as diferentes expressões culturais. (PONTIFÍCIO CONSELHO DA CULTURA, 1999, n. 29).

A pastoral, no campo da cultura, é uma forma de enriquecimento das culturas, como demonstrou o Papa João Paulo II: 
às culturas, a fé em Cristo dá uma dimensão nova, a da esperança do Reino de Deus. Os cristãos tem a vocação de inscrever no centro das culturas esta esperança duma terra nova e de céus novos. Muito longe de as ameaçar ou de as empobrecer, o Evangelho oferece-lhes um acréscimo de alegria e de beleza, de liberdade e de sentido, de verdade e de bondade. (JOÃO PAULO II, 1997).

\section{A pastoral da ação docente}

Para o pleno desenvolvimento da pastoral, na Universidade, merece destaque especial a atuação docente. Segundo o educador Arlin Migliazzo (2002), há quatro níveis de atuação de um professor católico no exercício de sua atividade docente:

a) assumir o seu papel de profissional exemplar no exercício do magistério: este nível é estritamente profissional. A consideração dos alunos e influência exercida pelo professor começa por aí: a exemplaridade de vida e a competência na disciplina que leciona. Apesar de não existir explicitamente uma relação direta entre compromisso profissional e fé, os alunos começam a fazer conexão entre a matéria que o professor leciona e a fé que ele pratica e valoriza. Ao demonstrar competência e bom ensino o professor também reflete o seu compromisso religioso;

b) interessar-se em promover a integração multidimensional dos conhecimentos (temas de estudo). Esta atitude é bem condizente com o meio acadêmico pós-moderno. Este nível ocorre quando o professor explora as possibilidades de integração da sua disciplina (ou programa de aprendizagem, como se costuma chamar atualmente) com as múltiplas abordagens da realidade. $\mathrm{O}$ professor católico entende que as pessoas operam sob a influência de prioridades muito diferentes e, às vezes, em competição, e mesmo contraditórias. Referências ao conhecimento religioso e à fé começam a aparecer;

c) promover a integração de valores com vistas à educação integral católica: neste nível encontra-se o professor que explora em sala de aula as questões de valor mais profundas, de natureza ética, moral, filosófica ou espiritual. É neste nível que é possível realmente envolver os estudantes pelas causas mais nobres;

d) comprometer-se em defender os valores, a visão cristã do mundo e a doutrina católica: é o nível mais alto e gratificante da atuação do professor católico e de sua integração com a Igreja. É, sobretudo, neste nível que as 
instituições católicas de educação deveriam se notabilizar. O Cristianismo oferece uma fundamentação consistente para os valores que o mundo e as pessoas aspiram. Os professores podem desafiar os estudantes a comparar as visões teóricas contemporâneas nas ciências naturais, ciências sociais, humanidades, entre outras, com as implicações de uma visão cristã. É neste nível de integração que a articulação concreta de uma visão cristã bem apresentada irá demonstrar aos estudantes, cristãos ou não, a real base dos valores a assumir na vida.

\section{Considerações finais}

Ao encerrar essas reflexões sobre a pastoral na PUCPR, queremos convidar toda a comunidade que compõe este complexo universitário e as instituições a ele vinculadas a se empenhar, cada um em seu âmbito específico, para transformar em vida as palavras e idéias aqui apresentadas. Como membros de uma organização cristã e católica, fazemos parte da Igreja. A Igreja não é uma simples estrutura institucional ou física, mas, acima de tudo, uma comunidade de pessoas irmanadas na mesma fé e seguidoras do único Mestre. Como Igreja, família dos cristãos, não podemos conservar apenas para nós a riqueza da mensagem cristã. Devemos expressar como Paulo de Tarso, o apóstolo missionário do primeiro século cristão, "Ai de mim se não evangelizar". Como foi visto nestas páginas, vivemos num mundo de profundas transformações em todos os setores, as quais nem sempre significam progresso no processo de humanização. Pelo contrário, muitas dessas transformações tem conduzido a humanidade a caminhos tortuosos, cujo futuro se mostra ameaçador. Mas, não podemos perder a esperança que nasce do Evangelho: "Coragem, eu venci o mundo" (Jo 16,33). Os jovens educandos são "o futuro da Igreja", como repetia frequentemente o Papa João Paulo II. Eles são a esperança de que, no amanhã, possamos viver num mundo mais humano, justo e fraterno. Nas mãos das novas gerações estão as sementes da construção de um mundo melhor, mais assemelhado ao Reino de Deus. Esforcemo-nos para que nossa presença educativa e evangelizadora, junto aos nossos jovens educandos, e também junto aos outros beneficiários da atuação de nossas organizações, alimente sua esperança, ilumine seus caminhos e lhes sirva de baliza num tempo em que as grandes referências parecem ter perdido seu valor. Que a mensagem cristã possa tocar seus corações a ponto de se comprometerem pela causa da verdade, do bem, da justiça, da solidariedade e da transcendência. 


\section{Referências}

A BÍBLIA de Jerusalém. 8. ed. São Paulo: Paulinas, 1981.

ALVES, Vicente Paulo. Universidade em pastoral: uma nova visão sobre o jeito convencional de fazer pastoral na universidade. Petrópolis, RJ: Vozes, 2002.

BENTO XVI. Discurso aos estudantes universitários de Roma e da região do Lácio. 15 dez. 2005.

O dom da comunhão. Audiência Geral, 29 de março de 2006.

CONCÍLIO ECUMÊNICO VATICANO II. Constituição pastoral Gaudium et Spes. Petrópolis, RJ: Vozes, 1966.

CONFERENCIA NACIONAL DOS BISPOS DO BRASIL - CNBB. Para uma pastoral da educação. São Paulo: Paulinas, 1986.

Evangelização e pastoral da universidade. São Paulo: Paulinas, 1988a.

Igreja, comunhão e missão na evangelização dos povos, no mundo trabalho, da política e da cultura. São Paulo: Paulinas, 1988b.

Educação, igreja e sociedade. São Paulo: Paulinas, 1992.

CONSELHO EPISCOPAL LATINO-AMERICANO - CELAM. Documento de Aparecida. São Paulo: CNBB; Paulinas; Paulus, 2007.

ECO, Umberto; MARTINI, Carlo Maria. Em que crêem os que não crêem? Rio de Janeiro: Record, 2000.

GERVILLA, Enrique. Posmodernidad y educación: Valores y cultura de los jóvenes. Madrid: Dykinson, 1993.

HEIDEGGER, Martin. Kant et le problème de la métaphysique. Paris: Gallimard, 1953.

INSTITUTO MARISTA. Missão educativa marista: um projeto para o nosso tempo. São Paulo: SIMAR, 2003.

JOÃO PAULO II. Encíclica Laborem Exercens. São Paulo: Paulinas, 1981. Encíclica Centesimus Annus. São Paulo: Paulinas, 1991. 

1994a.

. Carta apostólica Tertio Millennio Adveniente. São Paulo: Paulinas, 1994b.

Constituição apostólica Ex Corde Ecclesiae. Petrópolis, RJ: Vozes,

Discurso ao pontifício conselho da cultura, 15 de março de 1997.

Carta encíclica Fides et Ratio. São Paulo: Loyola, 1998.

Mensagem para o XXXVI dia mundial de oração pelas vocações. 25 de abril de 1999.

MIGLIAZZO, Arlin C. Teaching as na act of faith. New York: Fordham University Press, 2002.

PAULO VI. Exortação apostólica Evangelii Nuntiandi. São Paulo: Loyola, 1982. PONTIFÍCIO CONSELHO DA CULTURA. Para uma pastoral da cultura. São Paulo: Paulinas, 1999.

SANTA SÉ. Código de direito canônico [1983]. São Paulo: Loyola, 2002.

UNESCO. Conferência mundial sobre o ensino superior: tendências da educação superior para o século XXI. Paris: Unesco, 1998.

Recebido: 02/05/2008

Received: 05/02/2008

Aprovado: 06/06/2008

Approved: 06/06/2008 